\title{
The Relation of Population Burden and Financial Constraint to Entrepreneurial Choices of Rural Households
}

\author{
Mo Yuan \\ School of Finance \\ Nanjing University of Finance and Economics \\ Nanjing, China \\ Yi Xiao-lan* \\ CFSSS \\ Nanjing University of Finance and Economics \\ Nanjing, China \\ *Corresponding author
}

\author{
Zhang Yu-jia \\ School of International Economics and Trade \\ University of International Business and Economics \\ Beijing, China \\ Zhang Hui-min \\ School of Finance \\ Nanjing University of Finance and Economics \\ Nanjing, China
}

\begin{abstract}
In the background of population aging and the gradual release of fertility policy and based on the survey data of 237 rural households in Jiangsu province in 2016, this paper analyzes the impacts of child and elderly dependency ratio on rural households' financial constraint and entrepreneurship choice by logistic regression model. The empirical result shows that the child dependency ratio is positive for the entrepreneurial probability and when the financial constraint is low this effect may be enhanced. On the contrary, the elderly dependency ratio has negative impact on the entreprene urial probability. However, when we put financing amount into the model, this effect may be relieved. This research has certain enlightening significance for current fertility policy and entrepreneurship policy.
\end{abstract}

Keywords - Child Dependency Ratio; Elderly Dependency Ratio; Financial Constraint; Entrepreneurial Choices of Rural Households

\section{INTRODUCTION}

In 2018, the No. 1 Document of the Central Government clearly proposed to further promote the reform of the supply side of agriculture, improve the quality of agricultural development, and accelerate the cultivation of new kinetic energy for agricultural and rural development, and rural innovation and entrepreneurship is one of the important measures. Practice has proved that farmers often start their own businesses in the form of self-employment. Family population burden weakens the effect of household savings and capital accumulation, thus affecting financing capacity and entrepreneurial choices. However, at present, the age structure of China's population is not optimistic. The child dependency ratio is reduced from $26.8 \%$ at the end of 2007 to $22.9 \%$ at the end of 2016. The elderly dependency ratio has increased from

The research is supported by NSFC (No.71403116; 71803082), Chin Postdoctoral Science Foundation (No. 2017M610321), National Key R\&D Program (No. 2017YFD0401401)
$11.1 \%$ at the end of 2007 to $15.0 \%$ in the end of $2016^{1}$. According to statistics ${ }^{2}$, China's 16 to 59-year-old working-age population in 2017 was 90.19 million, 54.88 million less than the previous year, the sixth consecutive year of decline. By the end of 2017, China's population aged 65 and over has exceeded 150 million, accounting for $11.4 \%$ of the total population. The aging population ${ }^{3}$ is seriously affecting China's labor participation rate and labor productivity. At the same time, the total fertility rate of China's in 2016 which is 1.7 is still lower than the generation replacement level.

From a dynamic point of view, liberalizing the birth policy in an all-round way will help to increase the future labor force and improve the age structure of the population. However, the increase of child dependency ratio may lead to the increase of family Engel's coefficient and affect household debt and investment decisions, ultimately affecting economic growth. Therefore, the internal relationship between rural household population structure and entrepreneurial behavior is worth pondering. Whether there are differences in the influence of the elderly dependency ratio and the child dependency ratio on rural households' entrepreneurship, how households with different income levels behave, and how these problems are considered and explored will undoubtedly have strong theoretical and policy value for rural areas with relatively serious population aging. To further clarify the above problems, this paper defines rural households' entrepreneurship as the behavior of rural households in rural areas through

\footnotetext{
${ }^{1}$ Source: National Bureau of Statistics

http://data.stats.gov.cn/easyquery.htm?cn=C01\&zb=A0301\&sj=2016

2 National Bureau of Statistics, Statistical Communique of the

People's Republic of China on 2017 National Economic and Social Development.

${ }^{3}$ Usually, when a country or region accounts for $10 \%$ of the total population of the population over 60 years old, or $7 \%$ of the population of the elderly over 65 years old, it means that the country or region is in an aging society.
} 
self-employment to achieve business scale or establish new organizations and takes the sample of 237 households in Jiangsu Province as an example to study the impact of population structure on rural households' entrepreneurial choices in order to get the corresponding policy implications.

\section{LITERATURE REVIEW}

\section{A. Macro Perspective}

From a macro perspective, the population dependency ratio will have a significant negative impact on a country's savings rate and the increase of the population dependency ratio is the main reason why the savings rate of some economically backward countries does not increase with the increase of income( Leff,1969 ${ }^{[1]}$;Modigliani,2004 ${ }^{[2]}$ ). In the context of an aging population, the increase in the elderly dependency ratio has resulted in lower savings rates and higher consumption rates, which is not conducive to economic growth (Zhu Chao, et al, 2012 ${ }^{[3]}$; M Higgins, 1998 ${ }^{[4]}$; Leff, $\left.1969^{[1]}\right)$. On the contrary, in the case of a high proportion of the working-age population, the population is more productive and the burden of rising is lighter, resulting in more output into savings. Dynamically, in the short term, with the decline of birth rate, the consumption demand of residents is expanding. In the long run, the decline in the birth rate will lead to an increase in the degree of population aging and reduce the dynamic inefficiency of capital accumulation, which was accompanied by a decline in per capita income. In the current situation of the decrease of the child dependency ratio and the increase of the elderly dependency ratio in the future, the government needs to formulate appropriate population policies, properly encourage fertility and increase the proportion of the young population(Dong Lixia and Zhao Wenzhe, 2011) ${ }^{[5]}$.Therefore, many scholars have shown that the changes of family population structure brought about by population aging will affect the savings rate, capital accumulation and economic development through influencing factors of labor supply and population dependency ratio.

It is noteworthy that scholars have begun to explore the differences between the elderly dependency ratio and the child dependency ratio on economic development, consumption rate and savings rate. In terms of the impact on economic growth, demographic changes have played a significant role in the process of economic development in some Asian countries and regions. The reduction of population burden has greatly promoted the development of China's economy. The decrease of the child dependency ratio increases the contribution of labor input to economic growth, while the increase of the old-age dependency ratio restrains economic development to a certain extent, and this restraint is greater than the former (David E. Bloom and Jeffrey G. Williamson, $1998^{\text {[6] }}$; Zhang Qiong et al., 2011 ${ }^{[7]}$ ). Scholars have many disputes on the impact of residential consumption, and there are some differences in the conclusions of the study between rural areas and urban areas. In rural areas, the child dependency ratio and the total population dependency ratio are positively correlated with household consumption, while the elderly dependency ratio is negatively correlated with household consumption and has no significant impact, whereas in urban areas the opposite is true(Wang Yupeng, 2010) ${ }^{[8]}$. In terms of the impact on household savings, the increase of the old-age dependency ratio and the child dependency ratio will make the working-age population bear a heavy burden of dependency, thus reducing savings and bringing about a decline in the accumulation of social material capital (AJ Coale and EM Hoover, 1958) ${ }^{[9]}$. Previous studies have shown that the child dependency ratio reacts to the national savings rate, while the elderly dependency ratio has no significant effect. But in the long run, the child dependency ratio and the elderly dependency ratio are both Granger causes of the national savings rate. The influence of the child dependency ratio on the national savings gradually weakens, while the influence of the elderly dependency ratio is gradually strengthened (Xu Shengyan et al., $2013^{[10]}$; Song Qicheng and Yuan Kai, $2013^{[11]}$ ).

\section{B. Micro Perspective}

From a micro perspective, the rural child dependency ratio and the elderly dependency ratio have a significant impact on the allocation of household assets. Child rearing has a significant negative impact on household investment in financial markets (Li Wei, 2014) ${ }^{[12]}$. Under the background of the current aging population, China's elderly still maintain a high rate of labor participation after retirement, and changes in ways of care for the aged, increasingly scarce rural old-aged supporting resources, agricultural production and technological progress and labor intensity reduction, therefore, the rural elderly labor supply has its particularity. The effect of the elderly dependency ratio is contrary to that of the child, and it is positively correlated with investment in fixed assets, housing and insurance (D Davis, 1991 ${ }^{[13]}$; Liao Shaohong and Song Chunling, $2013^{[14]}$; Xiao Zhongyi, 2016 $\left.{ }^{[15]}\right)$. The total dependency ratio may affect households' entrepreneurial choice behavior by influencing household consumption, and this effect presents an inverted U-shaped (Moyuan et al., 2018) ${ }^{[16]}$.

To sum up, from the perspective of family, the choice of entrepreneurship is determined by the family population structure, financing constraints and the individual characteristics of the main family decision makers. Compared with population burden factors, scholars focus more on financing constraints and external financial environment when they study rural households entrepreneurship. They face varying degrees of financial constraints resulting in different career choices. Family wealth accumulation will constrain entrepreneurial choices (Lu Yajuan et al., 2014) ${ }^{[17]}$. As the financial system in China is still dominated by banks and credit constraints prevail in financial markets, formal financial credit is essential to ease the financial constraints of SMEs and promote innovation and entrepreneurship (Luigi Benfratello et al., 2008 ${ }^{[18]}$; BH Hall and J Lerner, $2009^{{ }^{19]}}$ ). Therefore, households generally face supply-oriented constraints in financing, and households with low financing demand become the main groups of households to start their own businesses (Zhang Yingliang et al., $2015^{[20]}$; Yang Jun et al., 2013 ${ }^{[21]}$ ). In terms of the external financial environment, scholars at home and abroad have found that since 1960, external financial constraints influenced farmers' decision-making a lot on whether to start a business or whether to hire workers, and the degree of impact is directly proportional to the level of entrepreneurship (AV Banerjee and AF Newman, 1993 ${ }^{[22]}$; C 
Ahlin and N Jiang, 2005 ${ }^{[23]}$; Liu Xinzhi and Liu Yusong, $\left.2015^{[24]}\right)$.

In a word, at the macro level, the impact of population structure on economic development, savings rate and capital accumulation in rural areas has been confirmed by many scholars, and the study has gone deep into the differences between the elderly dependency ratio and the child dependency ratio. At the micro level, the impact of the rural household's population burden on the allocation of financial assets and investment decisions has attracted many scholars' attention. However, the effects of the child dependency ratio and the elderly dependency ratio, which constitute the family dependency ratio, on entrepreneurial intention have not been discussed separately. Based on this, this paper intends to take financing constraints as an intermediate variable and select rural survey data in Jiangsu Province to study the differences between the elderly dependency ratio and child dependency ratio on entrepreneurial willingness and provide reference for the implementation and formulation of rural fertility policy and entrepreneurial policy.

\section{DAta SourCES AND DeSCRIPTIVE Statistics}

\section{A. Data Sources}

The data used in this study comes from the household survey conducted in Jiangsu Province during the summer vacation of 2017. After eliminating incomplete and untrue information, 237 valid questionnaires were obtained, including 121 in northern Jiangsu, 52 in central Jiangsu and 64 in southern Jiangsu. 91 entrepreneurial samples accounted for $38.4 \%$. The questionnaire covers family characteristics, household production and consumption, household risk preference, financing willingness and private financial survey, entrepreneurship and financing, etc. The basic characteristics of the samples are as follows. The data accords with normal distribution and satisfy the research needs.

TABLE I. ST ATISTICS OF SAMPLE BASIC CHARACT ERISTICS

\begin{tabular}{cll}
\hline Sample characteristics & \multicolumn{1}{c}{ Index } & Number of samples \\
\hline \multirow{3}{*}{ Householder' age (years) } & $\leq 35$ & 19 \\
& $(35,45]$ & 46 \\
& $(45,55]$ & 87 \\
& $>55$ & 85 \\
\hline \multirow{2}{*}{ Householder' education level } & Never attend the school & 14 \\
& Primary school & 51 \\
& Junior middle school & 113 \\
& Senior high school & 48 \\
& University or above & 11 \\
\hline \multirow{3}{*}{ Household income (ten thousand Yuan) } & $<5$ & 22 \\
& {$[5,20)$} & 77 \\
& {$[20,50)$} & 97 \\
& $\geq 50$ & 41 \\
\hline
\end{tabular}

\section{B. Descriptive Statistical Analysis}

\section{1) Population Burden and Entrepreneurial Choice}

The household population burden index adopted in this paper is the family population dependency ratio, the child dependency ratio and the elderly dependency ratio. Among them, the total dependency ratio is equal to the ratio of the number of people who need to be supported and supported by the family to the number of domestic labor force, and child dependency ratio is equal to the ratio of the number of children under 14 years old to the number of labor force, and elderly dependency ratio is equal to the ratio of the number of elders over 65 years old to the number of labor force. This paper divides the sample into entrepreneurs and non-entrepreneurs, and compares the possible impact of population dependency ratio on households' entrepreneurial choices and the differences between children and the elderly dependency ratio.

TABLE II shows that the average dependency ratio of the total population of the sample is 0.861 , and the household burden of the entrepreneurial households is greater than that of the non-entrepreneurial households and the sample average, which may be because the families with heavier population burden have a stronger willingness to increase their income to offset the increased consumption expenditure. As the number of labors rises, the dependency ratio drops first and then rises. Families with more labor can afford more people, thus may assume more responsibility for supporting the elderly and tend to have more children.

TABLE II. COMPARATIVE ANALYSIS OF THE TOT AL POPULATION DEPENDENCY RATIO

\begin{tabular}{|c|c|c|c|c|c|c|}
\hline Group by & Group category & Sample number & Average value & Standard deviation & Maximum value & Minimum value \\
\hline \multirow[t]{2}{*}{ Category of households } & entrepreneur & 91 & 1.046 & 1.131 & 5 & 0 \\
\hline & non-entrepreneur & 146 & 0.746 & 0.760 & 4 & 0 \\
\hline \multirow[t]{3}{*}{ Number of labor force } & 1 & 108 & 1.241 & 1.214 & 5 & 0 \\
\hline & 2 & 48 & 0.521 & 0.483 & 1.5 & 0 \\
\hline & $\geq 3$ & 81 & 0.557 & 0.287 & 1.3 & 0 \\
\hline Total & & 237 & 0.861 & 0.930 & 5 & 0 \\
\hline
\end{tabular}

In order to study the difference and relationship between the child dependency ratio and the elderly dependency ratio on the entrepreneurial behavior, this paper analyzes the child and the elderly dependency ratio respectively. From TABLE III, we can see that the child dependency ratio and the elderly dependency ratio of the entrepreneurs are greater than the 
average of the non-entrepreneurs, and compared with the elderly dependency ratio, the difference between the child dependency ratio of the entrepreneurs and the non-entrepreneurs is greater. This may be because the increasing burden of child care will increase household consumption and reduce household savings, making households' entrepreneurial willingness to increase income, while the impact of the elderly dependency ratio is less significant. By grouping the sample according to the number of household labor force, it is found that the trend of dependency ratio between child and the elderly is slightly different with the increase of the number of labor force, reflecting that the phenomenon of population aging in rural areas has been more serious, the elderly dependency ratio is greater than that of child and the elderly become the main burden of the family.

TABLE III. COMPARATIVE ANALYSIS OF CHILD DEPENDENCY RATIO AND ELDERLY DEPENDENCY RATIO

\begin{tabular}{lllllll}
\hline Group by & Group category & \multirow{2}{*}{ Sample number } & \multicolumn{2}{l}{ Average value } & \multicolumn{2}{l}{ Standard deviation } \\
\cline { 4 - 7 } & & & Child & Elderly & Child & Elderly \\
\hline Category of hous eholds & Entrepreneur & 91 & 0.457 & 0.589 & 0.639 & 0.724 \\
& Non-entrepreneur & 146 & 0.259 & 0.487 & 0.474 & 0.642 \\
\hline \multirow{3}{*}{ Number of labor force } & 1 & 108 & 0.528 & 0.713 & 0.716 & 0.907 \\
& 2 & 48 & 0.198 & 0.323 & 0.338 & 0.379 \\
& $\geq 3$ & 81 & 0.159 & 0.399 & 0.218 & 0.266 \\
\hline Total & & 237 & 0.335 & 0.527 & 0.550 & 0.675 \\
\hline
\end{tabular}

In order to further explore the difference of the dependency ratio between child and the elderly on the household consumption and entrepreneurial income, this paper divides the dependency ratio into groups and makes Fig. 1 and 2. From Fig. 1 , we can see that the influence of child dependency on entrepreneurial choice is more in line with the inverted U rule. That is to say, when there are fewer children, households are less willing to start their own businesses because of less household consumption at present and less burden on children's education and marriage in the future. With the increasing burden of child care, households' willingness to increase savings by increasing income and smoothing consumption is strengthened. When the burden of child care exceeds a certain limit, households are unable to complete the initial capital accumulation, and are constrained by financing. The influence of elderly dependency ratio on entrepreneurial willingness is not significant.

Fig. 2 shows that, with the increase of child dependency ratio, household income shows an overall upward trend, which shows that the greater burden of support will promote farmers to work harder to obtain income, and the increase of income will also enhance the ability of farmers to support and fertility. Compared with the elderly dependency ratio, the rise of child dependency ratio can stimulate households' willingness to increase incomes, which may be because the increase in the number of children can increase household consumption expectations to a greater extent, thus contributing to current income and savings.

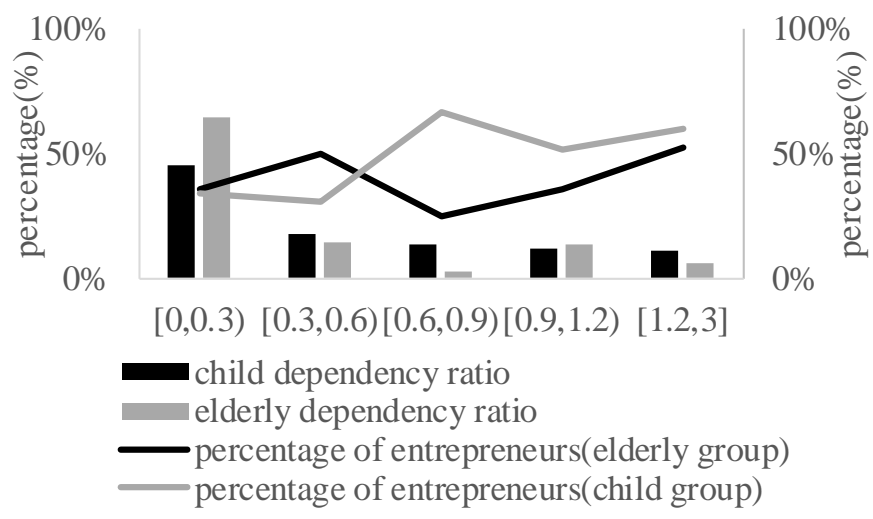

Fig. 1. Proportion of entrepreneurial households in different population dependency ratios

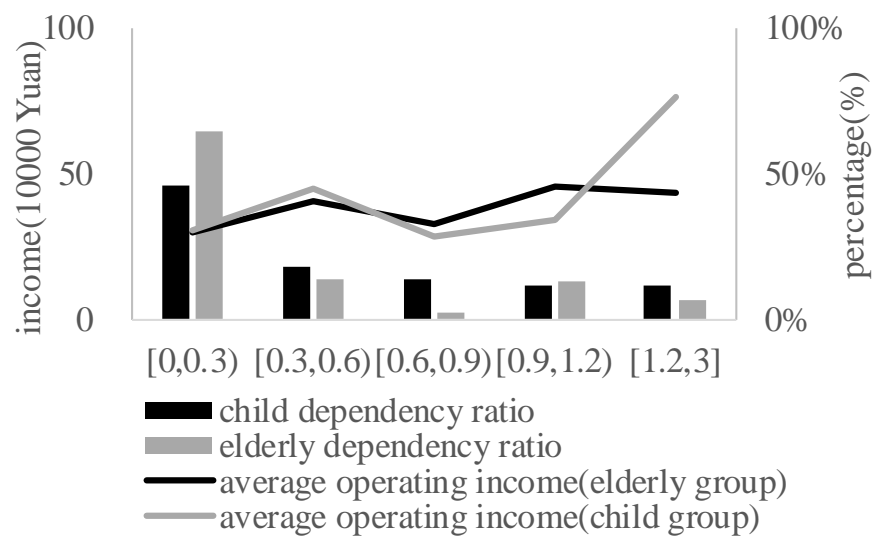

Fig. 2. Average value of household income in different population dependency ratios

2) Other Influencing Factors of Entrepreneurial Choice

Household's population structure (family labor force, householder's age, etc.) has its unique characteristics. The number and structure of the household population will affect the choice of whether or not the entrepreneurs employ the labor force, and then affect the entrepreneurial cost and choice. Some scholars believe that the number of labor force of entrepreneurial households is slightly higher than the average 
level (Hao Chaoyan et al., 2012) ${ }^{[25]}$. However, in the sample, the difference between the average number of labor force of entrepreneurial households and non-entrepreneurial households is not significant. In terms of householder's age, the financial constraints of middle-aged entrepreneurs are lower than those of older entrepreneurs. Middle-aged entrepreneurs have better entrepreneurial environment than young and old entrepreneurs
(Yang Jun et al., $2013^{\text {[21]; Zhang Yingliang et al., 2015 }}{ }^{[22]}$ ) because of their experience advantages (age, physiological advantages). The influence of age on households' entrepreneurial choices may be nonlinear (Chen Wenchao et al., $2014)^{[26]}$. The average age of the entrepreneurs in the sample is about 49 years old, which is consistent with the previous research results.

TABLE IV. COMPARATIVE ANALYSIS OF RURAL HOUSEHOLD LABOR FORCE

\begin{tabular}{llllll}
\hline Group by & Group category & Sample number & Average value & Standard deviation & Maximum value \\
\hline Entrepreneur & 91 & 1.890 & 1.090 & 5 & 1 \\
Non-entrepreneur & 146 & 2.034 & 1.033 & 5 & 1 \\
Total & 237 & 1.979 & 1.055 & 5 & 1 \\
\hline
\end{tabular}

TABLE V. AGE DESCRIPTION ST ATISTICS OF HOUSEHOLDER

\begin{tabular}{llll}
\hline Group by & Group category & Sample number & Average value \\
\hline$\leq \mathbf{3 5}$ & $52.63 \%$ & 0.513 & 19 \\
$\mathbf{( 3 5 , 4 5 ]}$ & $43.48 \%$ & 0.501 & 46 \\
$\mathbf{( 4 5 , 5 5 ]}$ & $44.83 \%$ & 0.500 & 87 \\
$>\mathbf{5 5}$ & $25.88 \%$ & 0.441 & 85 \\
Total & $38.40 \%$ & 0.487 & 237 \\
\hline
\end{tabular}

Compared with the family population structure, the impact of households' financing constraints, financial environment and individual characteristics of family decision-makers on their entrepreneurship is more concerned by scholars. This paper divides the financing constraints into internal and external parts, and uses operating income, household fixed assets and farmland area to represent the internal financing constraints, that is, the level of household wealth of rural households, the times and amount of loans to represent the external financing constraints. In the samples, entrepreneurs' indicators except fixed assets are significantly higher than non-entrepreneurs' indicators, which shows that entrepreneurs' financing constraints are small. Because credit rationing still exists in the rural financial market, increasing households' credit availability and easing their financial constraints will help promote their entrepreneurship activities. It is noteworthy that, in view of the rural land contractual management right mortgage loan has already begun to pilot, this paper uses farmland area as an indicator of household wealth level. The empirical results show that the average farmland is larger, which can alleviate the financial pressure of entrepreneurship to a certain extent.

Regarding the regional financial environment, the formal financial environment is characterized by 'the distance between banks and households" and "whether there are loan officers" and the informal financial environment is characterized by 'the types of local informal financial activities". The regional financial environment in which entrepreneurial households are located is obviously better than that of non-entrepreneurial households. Therefore, optimizing formal financial services, standardizing management and guiding informal financial activities are conducive to creating a good atmosphere for entrepreneurship.

TABLE VI. COMPARATIVE ANALYSIS OF FINANCING CONSTRAINTS

\begin{tabular}{|c|c|c|c|}
\hline & Variable & Entrepreneur & Non-entrepreneur \\
\hline \multirow{3}{*}{ Internal financing constraints } & Average operating income (10000 Yuan) & $19.452(25.340)$ & $1.263(3.027)$ \\
\hline & Average household fixed assets (10000 Yuan) & $10.008(21.655)$ & $12.225(58.960)$ \\
\hline & Average value of farmland (mu) & $11.414(26.129)$ & $9.253(57.721)$ \\
\hline \multirow{2}{*}{ External financing constraints } & Mean number of loans (time) & $0.495(0.689)$ & $0.156(0.418)$ \\
\hline & Mean value of loan amount (10000 Yuan) & $7.629(24.044)$ & $2.811(11.293)$ \\
\hline \multirow{3}{*}{ Regional financial environment } & $\begin{array}{l}\begin{array}{l}\text { Mean value of distance between bank and } \\
\text { household }(\mathrm{km})\end{array}\end{array}$ & $2.612(2.397)$ & $3.391(2.376)$ \\
\hline & Are there any loan officers in this township? & $0.527(0.502)$ & $0.363(0.483)$ \\
\hline & Types of local informal financial activities (species) & $1.747(0.914)$ & $1.384(0.816)$ \\
\hline
\end{tabular}

In terms of personal characteristics of householders, the following five indicators are adopted (see TABLE VII). In the current rural areas, the majority of family decision-makers are men, and there is no significant gender difference between entrepreneurs and non-entrepreneurs. Farmers with migrant experience are more inclined to obtain stable income from migrant work in order to avoid the uncertainty of entrepreneurship. When measuring entrepreneurial spirit, the method used in this paper is to ask farmers whether they will choose to retire if they win a million dollars, and regard the farmers who choose "no" as maintaining entrepreneurial spirit. In measuring risk awareness, the method used in this paper is to ask farmers "if there are two jobs, a salary of 2800 Yuan, the other half of the probability of the salary is 5600 Yuan, half of the probability is 0 Yuan, which will you choose?" Choosing the first job is regarded as risk aversion, choosing the second job as risk preference, and choosing "both can" as risk neutrality. Statistical results show that entrepreneurs have more entrepreneurial spirit, and because entrepreneurs take greater risk than migrant workers, so the risk-preference are more inclined to entrepreneurship. In addition, the proportion of entrepreneurs increases gradually with the level of education. Householders with higher education level have advantages in identifying entrepreneurial opportunities, learning entrepreneurial knowledges and accumulating family wealth. 
TABLE VII. CHARACTERISTICS OF RURAL HOUSEHOLDER

\begin{tabular}{|c|c|c|c|c|}
\hline Characteristics of householder & Index & Entrepreneur & Non-entrepreneur & $\begin{array}{l}\text { Number of } \\
\text { samples }\end{array}$ \\
\hline Gender & Male occupation ratio & $96.70 \%$ & $97.95 \%$ & 237 \\
\hline Experience of migrant work & $\begin{array}{l}\text { The proportion of households with this } \\
\text { experience }\end{array}$ & $53.85 \%$ & $60.96 \%$ & 237 \\
\hline Entrepreneurial spirit & $\begin{array}{l}\text { The proportion of entrepreneurs with } \\
\text { entrepreneurial spirit }\end{array}$ & $72.53 \%$ & $58.22 \%$ & 237 \\
\hline \multirow{5}{*}{ Education level } & Never attend the school & $28.57 \%$ & $71.43 \%$ & 14 \\
\hline & Primary school & $33.33 \%$ & $66.67 \%$ & 51 \\
\hline & Junior middle school & $38.05 \%$ & $61.95 \%$ & 113 \\
\hline & Senior high school & $45.83 \%$ & $54.17 \%$ & 48 \\
\hline & University or above & $45.45 \%$ & $54.55 \%$ & 11 \\
\hline \multirow{3}{*}{ Risk awareness } & Risk preference & $27.47 \%$ & $13.01 \%$ & 44 \\
\hline & Risk aversion & $54.95 \%$ & $67.12 \%$ & 148 \\
\hline & Risk neutral & $17.58 \%$ & $19.86 \%$ & 45 \\
\hline
\end{tabular}

To sum up, entrepreneurial choice is the result of the combined effect of the main family decision-makers' personal characteristics, family population structure and financing constraints. When the wealth level is high and the financing constraints are small, the increase of the burden of population support will promote entrepreneurship income. Among them, the effect of child dependency ratio is more significant than that of elderly dependency ratio. From the dynamic point of view, the increase of the burden of population support will also make the family Engel coefficient rise, the speed of wealth accumulation will decline, and the financing constraints will increase. At this time, households' entrepreneurial desire may not increase but decrease. In order to further explore the role of financing constraints in the family population burden on households' entrepreneurial choices, the following paper will do empirical analysis.

\section{EMPIRICAL ANALYSIS}

\section{A. Model Construction and Variable Selection}

In general, linear regression models rely on default variables as interval variables. The households' entrepreneurship choice studied in this paper is a typical two-class variable problem, and Logistic model is just suitable for this kind of problem. Logistic model is based on binary selection theory. The model function is probability distribution function. The concrete form is as follows:

$$
\begin{aligned}
& P_{i}=F\left(Z_{i}\right)=e^{Z_{i}} / 1+e^{Z_{i}}=1 / 1+e^{-Z_{i}} \\
& \text { Converted to a linear function form: } \ln \frac{P_{i}}{1-P_{i}}=Z_{i} \\
& Z_{i}=\alpha+\beta_{i} L_{i}+\delta_{i} F_{i}+\gamma_{i} L_{i} \times F_{i}+\Omega_{i} C_{i}+\mu
\end{aligned}
$$

In formula (1), $P_{i}$ is the probability that the household makes a certain choice, $Z_{i}$ is the dependent variable, $Z=1$ means that the household chooses to start a business, otherwise $Z=0 . \beta$, $\delta, \gamma, \Omega$ represent the regression coefficients of dependent variables, interaction terms, and control variables, respectively. $L$ and $F$ are independent variables, $L \times F$ is an interaction term, $C$ is a control variable, $\alpha$ is a constant term of the equation, and $\mu$ is the error term. Descriptive statistics of related variables are

\begin{tabular}{|c|c|c|c|c|c|c|}
\hline $\begin{array}{l}\text { Variable } \\
\text { types }\end{array}$ & Variable name / expression & Variable definition and value & Mean & $\begin{array}{l}\text { Standard } \\
\text { deviation }\end{array}$ & $\begin{array}{l}\text { Maximum } \\
\text { value }\end{array}$ & $\begin{array}{l}\text { Minimum } \\
\text { value }\end{array}$ \\
\hline $\begin{array}{l}\text { Dependent } \\
\text { variable }\end{array}$ & $\begin{array}{l}\text { Does the household choose } \\
\text { entrepreneurship / }\end{array}$ & Yes $=1 ;$ no $=0$ & 0.384 & 0.487 & 1 & 0 \\
\hline \multirow{12}{*}{ Key variable } & $\begin{array}{l}\text { Lower group of child dependency ratio } \\
\text { /chbugroups }\end{array}$ & {$[0,0.3)=1 ;$ other $=0$} & 0.641 & 0.481 & 1 & 0 \\
\hline & $\begin{array}{c}\text { Higher group of child dependency ratio/ } \\
\text { chbugroupl }\end{array}$ & {$[0.6,+\infty)=1 ;$ other $=0$} & 0.219 & 0.415 & 1 & 0 \\
\hline & $\begin{array}{c}\text { Lower group of elderly dependency ratio } \\
\text { /sebugroups }\end{array}$ & {$[0,0.3)=1 ;$ other $=0$} & 0.456 & 0.499 & 1 & 0 \\
\hline & $\begin{array}{c}\text { Higher group of elderly dependency ratio } \\
\text { /subugroupl }\end{array}$ & {$[0.6,+\infty)=1 ;$ other $=0$} & 0.367 & 0.483 & 1 & 0 \\
\hline & Number of labor force / labor & Actual number of labor force & 1.979 & 1.055 & 5 & 1 \\
\hline & Householder's age /age & Actual age of the head of the household & 51.603 & 10.273 & 65 & 28 \\
\hline & Financing demands / finance & $\begin{array}{c}\text { Logarithmic form of the average amount } \\
\text { of each financing }\end{array}$ & 0.536 & 1.091 & 5.303 & 0 \\
\hline & Family wealth/capital & Logarithmic form of fixed assets & 1.880 & 0.762 & 6.560 & 0.690 \\
\hline & Farmland area group /land & $\begin{array}{c}\text { "farmland area } \leq 5 "=1 ; " 5<\text { farmland } \\
\text { area } \leq 10 "=2 ; \text { other }=3\end{array}$ & 1.384 & 0.670 & 3 & 1 \\
\hline & Distance/distance & $\begin{array}{l}\text { The distance between rural households and } \\
\text { the most frequently visited banks }\end{array}$ & 3.092 & 2.409 & 12 & 0.1 \\
\hline & Infomal financial activity /variety & Types of infommal financial activities in townships & 1.523 & 0.871 & 5 & 0 \\
\hline & Loan officer/credit & $\begin{array}{l}\text { Whether there is a loan officer in the } \\
\text { township, yes =1; no }=0\end{array}$ & 0.426 & 0.496 & 1 & 0 \\
\hline
\end{tabular}
shown in TABLE VIII.

TABLE VIII. DESCRIPTION OF VARIABLE DEFINITION 


\begin{tabular}{|c|c|c|c|c|c|c|}
\hline \multicolumn{7}{|c|}{ Cont. to TABLE VIII } \\
\hline \multirow{5}{*}{$\begin{array}{l}\text { Control } \\
\text { variable }\end{array}$} & Risk attitude/riskpref & Preference $=1$; other $=0$ & 0.186 & 0.390 & 1 & 0 \\
\hline & Risk attitude /riskhate & Aversion $=1$; other $=0$ & 0.625 & 0.485 & 1 & 0 \\
\hline & Entrepreneurial spirit/spirit & Yes $=1 ;$ no $=0$ & 0.363 & 0.482 & 1 & 0 \\
\hline & Migrant working experience /work & $\begin{array}{l}\text { Whether hous eholder has a work } \\
\text { experience, yes }=1 ; \text { no }=0\end{array}$ & 0.582 & 0.494 & 1 & 0 \\
\hline & Education level / edudum & $\begin{array}{l}\text { Whether householdereducation level above junior } \\
\text { high school, yes }=1 \text {, other }=0\end{array}$ & 0.249 & 0.433 & 1 & 0 \\
\hline
\end{tabular}

\section{B. Model Estimation Results and Discussion}

In this paper, using SPSS22.0 software, Logistic regression was performed on 237 samples. Firstly, the child and elderly dependency ratios were introduced into the model for significance test, and then the control variables were gradually increased or decreased for comparison. The regression results are shown in TABLE IX.

TABLE IX. ESTIMATION RESULTS OF ENTREPRENEURIAL CHOICES BY LOGISTIC MODEL

\begin{tabular}{|c|c|c|c|c|}
\hline Dependent variable & $Z$ & $Z$ & $Z$ & $Z$ \\
\hline Independent variables & Model I & Model II & ModelIII & Model IV \\
\hline chbugroups & $0.279(0.427)$ & $0.379(0.508)$ & $0.150(0.150)$ & $0.425(0.512)$ \\
\hline chbugroupl & $1.360^{* * * *}(0.495)$ & $1.344^{* *}(0.602)$ & $0.896(0.613)$ & $1.421^{* * *}(0.616)$ \\
\hline sebugroups & $-0.963^{* * *}(0.390)$ & $-0.944^{*}(0.487)$ & $-0.842^{*}(0.482)$ & $-1.290^{* *}(0.506)$ \\
\hline sebugroupl & $-0.822^{* * *}(0.396)$ & $-0.997^{* *}(0.501)$ & $-0.960^{*}(0.495)$ & $-1.370^{* * *}(0.521)$ \\
\hline labor & - & $-0.111(0.192)$ & $-0.067(0.194)$ & $-0.145(0.193)$ \\
\hline age & - & $-0.042^{*}(0.022)$ & $-0.045^{* *}(0.022)$ & $-0.042^{*}(0.022)$ \\
\hline finance & - & $0.464^{* * * *}(0.157)$ & - & - \\
\hline capital & - & $0.180(0.205)$ & $0.194(0.207)$ & $0.190(0.208)$ \\
\hline land & - & $0.384(0.255)$ & $0.416(0.254)$ & $0.406(0.258)$ \\
\hline distance & - & $-0.189^{* *}(0.071)$ & $-0.190^{* * * *}(0.071)$ & $-0.206^{* * * *}(0.073)$ \\
\hline variety & - & $0.462^{* *}(0.188)$ & $0.466^{* *}(0.185)$ & $0.476^{* *}(0.187)$ \\
\hline credit & - & $0.705^{* *}(0.344)$ & $0.697^{* *}(0.343)$ & $0.736^{* *}(0.350)$ \\
\hline riskpref & - & $0.700(0.527)$ & $0.676(0.524)$ & $0.794(0.537)$ \\
\hline riskhate & - & $0.014(0.416)$ & $0.043(0.413)$ & $0.036(0.423)$ \\
\hline spirit & - & $0.322(0.352)$ & $0.303(0.352)$ & $0.300(0.358)$ \\
\hline work & - & $-1.096^{* * * *}(0.396)$ & $-1.124^{* * * *}(0.397)$ & $-1.156^{* * *}(0.409)$ \\
\hline edudum & - & $0.102(0.381)$ & $0.126(0.383)$ & $0.051(0.390)$ \\
\hline finance $\times$ chbugroups & - & - & $0.341^{*}(0.203)$ & - \\
\hline finance $\times$ chbugroupl & $\overline{-}$ & $\overline{-}$ & $0.807^{* *}(0.383)$ & $\overline{-}$ \\
\hline finance $\times$ sebugroups & - & - & - & $0.657^{* *}(0.277)$ \\
\hline finance $\times$ sebugroupl & - & - & - & $0.616^{* * * *}(0.238)$ \\
\hline Constant & $-0.236(0.449)$ & $0.794(1.551)$ & $1.037(1.531)$ & $1.098(1.595)$ \\
\hline -2Log likelihood & $300.811^{* * 4 \times 4}$ & 253.160 & $246.389^{* * 2 \times 19}$ & $241.439^{* * 4 \%}$ \\
\hline
\end{tabular}

Note: $(1) *, * *, * * *$ respectively indicate that the test value is significant at the confidence level of $10 \%, 5 \%$, and $1 \%$. The standard error is indicated in the brackets under the explanatory variable coefficient. (2) Model I only studies the influence of child and elderly dependency ratio. Model II adds other key variables and control variables based on Model I. (3) Model III adds the interaction items finance $\times$ chbugroups and finance $\times$ chbugroupl to the model II and removes the finance item. (4) Model IV adds the interaction items finance $\times$ sebugroups and finance $\times$ sebugroupl to the model II and removes the finance item.

The results show that: firstly, the child dependency ratio has a positive impact on entrepreneurial willingness, while the elderly dependency ratio and the age of householders have a negative impact. Child rearing was significantly higher than that of the higher group at $1 \%$ level, and the coefficient was positive, which means that families with more children tend to have a stronger desire to start a business. At the same time, the interaction terms of model III, finance $\times$ chbugroups and finance $\times$ chbugroupl, passed the $10 \%$ and $5 \%$ significance tests respectively and the coefficients were positive. That is, if households raise their financing ability, the positive effect of child dependency ratio will be enhanced.

The lower group and the higher group have significant differences and negative coefficients at $5 \%$ and $1 \%$ respectively, which may be due to the higher Engel coefficient, fewer saving, slower accumulation of family wealth and less entrepreneurial intention in the context of the current aging population in rural areas. Meantime, the interaction terms, finance $\times$ sebugroups and finance $\times$ sebugroupl, passed $5 \%$ and $1 \%$ of the significance tests respectively and the symbols were positive, showing that the improvement of family financing ability can weaken the negative effects of the burden on the elderly population. The age of the householder is $5 \%$ and the coefficient is negative. This shows that when the householder is into middle age, with the continued growth of his age, the process of accumulation of family wealth is basically completed, the burden of population support becomes smaller, and the entrepreneurial willingness also declines. 
Secondly, there are financing constraints on entrepreneurial choice behavior. Whether there are credit officers, the types of local informal financial activities, financing demands and the distance between banks and households are significant at the levels of $5 \%, 5 \%, 1 \%$ and $1 \%$, respectively. The first three coefficients are positive, while the distance is negative. In this paper, the average loan amount each time in the past two years is used to measure the financing level of households. The larger the amount, the stronger the financing capacity of households, and the easier it is to start a business. Whether there are credit officers and the types of local informal financial activities in the township are used to measure the formal and informal financial environment respectively. The positive correlation between the two is consistent with the existing research. (Hu Jinyan and Zhang Bo, 2014) ${ }^{[27]}$. Households closer to banks are in a better financial environment and are more likely to get the latest credit information and preferential policies from banks, thus forming a geological trust relationship, so the entrepreneurial possibility is greater. Fixed assets are not significant, possibly because rural household housing is often priceless, and households can not provide qualified collateral when financing. The farmland area is not significant, which may be due to the fact that the reform of "three rights separation" of rural land is still in the process of implementation. The ratio of land property confirmation of samples is $75.95 \%$. The farmland plays a smaller role in increasing households' income and providing loan collateral to ease credit constraints. Moreover, the non-agricultural entrepreneurs' insensitivity to this variable also weakens the dependence of agricultural entrepreneurs on farmland. Finally, we discuss the influence of other control variables. The experience of migrant work significantly suppressed the entrepreneurial willingness. Under the background of new-type urbanization, the attraction of cities to farmers is far greater than that of countryside. How to guide and support farmers from "working economy" to "entrepreneurship economy" through policies has become an urgent problem to be solved. In addition, entrepreneurial spirit, type of risk preference and level of education have no significant impact, which reflects that most farmers have small scale of entrepreneurship, low technical level. At the same time, households with the junior middle school education level still can not form a professional knowledge system, which affects the significance of this item.

\section{CONCLUSIONS AND IMPLiCATIONS}

Based on 237 rural household samples, this paper compares and analyzes the difference of population burden between entrepreneurs and non-entrepreneurs, and makes regression analysis using Logistic model. (1) Families with heavier child dependency ratio have a stronger desire to increase their income from entrepreneurship. If the ability to raise funds is enhanced, the positive effect will be enhanced. (2) Elderly dependency ratio has a negative effect on households' entrepreneurial choices. In rural areas, the aging population is more serious, the Engel coefficient of rural households with heavier burden of elderly support is larger, and the accumulation of family wealth is slower, so the entrepreneurial intention is smaller. But, the improvement of family financing ability can weaken this negative effect. (3) Family financing demand and regional financial environment significantly affect households' entrepreneurial willingness, while experience of migrant work has an inhibitory effect on entrepreneurial desire.

In view of the above conclusions, this paper draws the following enlightenment: First, we should continue to implement the population policy of encouraging births, and accelerate the improvement of supporting measures such as child-care subsidies, maternity leave system, incentives and public service system and affect family investment and entrepreneurial decisions by changing the child dependency ratio. At the same time, we should provide vocational training and technical services for the elderly who still have the ability to work, improve the rural pension mechanism, and alleviate the aging problem of the rural population. Second, we should improve regional financial services, standardize informal financial activities, improve the availability of rural households' formal credit, ease the financing constraints, and use mobile banking technology, community financial service stations and other modes to improve the opportunities for entrepreneurs to obtain financial services and information guidance. Third, we should support migrant workers returning home to start their own businesses. We will continue to optimize and improve policies that combine industry with finance, public services and social management, such as technical training for returning migrant workers and lower preferential tax rates, to meet the actual needs of returning farmers.

\section{REFERENCES}

[1] Leff \& Nathaniel H. Dependency Rates and Savings Rate[J]. A merican Economic Review, 1969, 59(5):886-896.

[2] Modigliani \& F., S Cao. The Chinese Saving Puzzle and the Life-cycle Hypothesis [J]. Journal of Economic Literature, 2004, 42 (01): 145-170.

[3] Zhu Chao, Zhou Wei, Zhang Linjie. Savings Investment Behavior and Population Structure Effect in External Equilibrium-Evidence from Asia[J].China Population Science,2012(01):39-50.

[4] M Higgins. Demography, National Savings and International Capital Flows [J]. International Economic Review, 1998, 39 (02): 343-369.

[5] Dong Lixia, Zhao Wenzhe. Population Structure and Saving Rate: A Study Based on Endogenous Population Structure[J].Financial Research,2011(03):1-14.

[6] David E. Bloom, Jeffrey G Williamson. Demographic Transition and Economic Miracles in Emerging Asia[J].WBER Working Papers No.6268,1998(03):419-455.

[7] Zhang Qiong, Bai Chongen. Support Burden, Resident Health and Economic Growth - Population Characteristics Influencing the Economic Development of Counties and Cities in China [J].Financial Research, 2011, 37 (07): 17-27.

[8] Wang Yupeng. Research on the Influence of Population Aging on the Consumption Behavior of Urban Residents in China[J]. China Population Science, 2011(01): 64-73+112.

[9] AJ Coale, EM Hoover. Economics and the Social Sciences: Population Growth and Economic Development in Low-Income Countries. A Case Study of India's Prospects [J]. Journal of Radio analytical \& Nuclear Chemistry, 2015, 54 (04): 1-12.

[10] Xu Shengyan, Liu Peisong. Study on the Long-term Dynamic Impact of Population Age Structure Change on Chinese Residents' Savings[J]. Economic Survey, 2013(05): 111-116.

[11] Song Qicheng, Yuan Kai. The Impact of Population Rearing Ratio Change on Household Saving Rate in China-An Empirical Study Based on Time Series[J].Journal of Chongqing University of Technology(Social Science Edition),2013,27(11):14- 19. 
[12] Li Wei. The Population Structure Factors behind High Investment-Based on the Research of Provincial Dynamic Panel Data Model[J]. Population and Economy, 2014(01): 47-54.

[13] D Davis. Long Lives: Chinese Elderly and the Communist Revolution [M]. Harvard University Press, 1991, 13 (03): 280.

[14] Liao Shaohong, Song Chunling. Labor Supply Behavior of Rural Old People in China-Evidence from Rural Areas in Shandong Province[J]. Population and Economy, 2013(02): 60-68.

[15] Xiao Zhongyi, Zhou Yiping, Li Siming. Study on the Characteristics of Rural Population and Asset Allocation of Residents' Consumption Finance[J].Journal of Chongqing University of Technology(Social Sciences),2016,30(02):25-35.

[16] Mo Yuan, Zhang Yijia, Xu Shaoda. Family Demographic Characteristics and Farmers' Entrepreneurial Choice-An Empirical Study from Jiangsu Province[J]. Northwest Population, 2018, 39(02): 24-31+40.

[17] Lu Yajuan, Zhang Longyao, Xu Yuzhen. Financial Availability and Rural Family Entrepreneurship-An Empirical Study Based on CHARLS Data[J]. Economic Theory and Business Management, 2014(10): 89-99.

[18] Luigi Benfratello, Fabio Schiantarelli, Alessandro Sembenelli. Banks and Innovation Microeconometric Evidence on Italian Firms [J]. Journal of Financial Economics, 2008, 90 (02): 197-217.

[19] BH Hall, J Lerner. The Financing of R\&D and Innovation [J]. Handbook of the Economics of Innovation, 2009 (01): 609-639.
[20] Yang Jun, Zhang Longyao, Jiang Yan. Community Financial Resources, Family Finance and Farmer Entrepreneurship - Based on the CHARLS Survey Data [J].Agricultural Technology Economy, 2013 (11): 71-79.

[21] Zhang Yingliang, Gao Jing, Zhang Jianfeng. Research on Regular Financial Credit Restriction of Entrepreneurial Farmers: An Empirical Analysis Based on 939 Farmer Entrepreneurship Surveys [J].Agricultural Technology Economy, 2015 (01): 64-74.

[22] AV Banerjee, AF Newman. Occupational choice and the process of development [J]. Journal of Political Economy, 1993, 101 (02): 274-298.

[23] C Ahlin, N Jiang. Can micro-credit bring development? [J]. Journal of Development Economics, 2005, 86 (01): 1-21.

[24] Liu Xinzhi, Liu Yusong. The Impact of Migrant Workers' Experiences on Farmers' Entrepreneurial Behavior Decisions-Based on Empirical Analysis of 518 Farmers' Entrepreneurship Surveys[J].Agricultural Technology Economy,2015(06):4-14.

[25] Hao Zhaoyan, Ping Xinqiao, Zhang Haiyang, Liang Shuang. Farmers' Entrepreneurial Choice and Its Influencing Factors-Evidence from "Rural Financial Investigation”[J].China Rural Economy, 2012(04): 57-65+ 95.

[26] Chen Wenchao, Chen Wen, Jiang Lihua. An Analysis of the Influencing Factors of Migrant Workers Returning to Hometown for Entrepreneurship[J]. China Population Science, 2014(02): 96-105.

[27] Hu Jinxi, Zhang Bo. Social Network, Private Financing and Family Entrepreneurship-An Empirical Analysis Based on the Differences between Urban and Rural Areas in China[J].Financial Research, 2014(10):148-163. 